\title{
French back Spot satellite
}

\section{Paris}

FRANCE has decided to back its commercial remote-sensing programme until the end of the century by giving the go-ahead to build a fourth Spot satellite. The decision, announced after a cabinet meeting last week, should mean an extra FF200 million ( $\$ 31$ million) in next year's budget for the national space research centre (CNES).

At a time when the US Landsat remotesensing satellites have been given only a temporary reprieve pending a review by the new Bush administration (see Nature 338, 365; 1989), the French government is more than ever committed to Spot.

New political interest in environmental issues, together with France's longstanding enthusiasm for space technology, makes the Spot programme an ideal vehicle for national prestige. But Spot-1, launched in 1986, has already overrun its intended life by one year and CNES has decided to take up its option to launch Spot- 2 in November aboard an Ariane 40 rocket. CNES had originally hoped to delay the launch so long as Spot-1 continued to function, in order to save money.

Spot-4 embodies some significant new features compared with its predecessors, Spot-1, 2 and 3, which will make it more useful for monitoring changes in vegetation throughout the world. Spot-1's two high-resolution visible (HRV) chargecoupled sensors will be updated and their bandwidth extended to the medium infrared. The new sensors will be made by the French company Thomson instead of the US Fairchild which supplied Spot-1,2 and 3. The switch to a French company, say the satellite's makers, Matra-Espace, should allow better control of component quality. Interestingly, Matra last week acquired three of Fairchild's communications and space divisions. Spot-4's two data tape-recorders will also be made in France, by Enertec, instead of by the US company Odetics. One of the two Odetics recorders aboard Spot-1 has failed, leaving the satellite unable to send pictures of some areas of the globe.

The change to French manufacturers could also be because a military satellite, Helios, due to be launched in 1993, shares its chassis and many components with Spot-4. The technology will also be useful in the development of the European polar platform contribution to the Freedom space platform. These factors may have helped secure government support.

Despite the 'green' aspect of the decision to back Spot-4, it will be less useful to monitor environmental change than its original design intended. A multispectrum 'vegetation' instrument with a scanning width of $2,220 \mathrm{~km}$ and a resolution of 60 $\mathrm{km}$, which would have made possible global change monitoring, has been dropped. Additional data-processing facilities, both within the satellite and on the ground, would have increased costs by as much as FF1,000 million.

Construction costs for Spot-4 are down to about FF3,000 million, compared with the FF5,000 million for Spot-1, and its life has been extended from two to four years. Nevertheless, Paul Quilès, minister for posts, telecommunications and space, has said that sales of Spot pictures should balance operating costs (FF210 million in 1988) by 1993.

Spot-4 is scheduled for a 1995 launch. but should be ready to take over if Spot-3. due for launch in 1992, fails. Peter Coles

\section{US-Soviet earthquake collaboration}

\section{San Francisco}

A COMPREHENSIVE scientific agreement between the United States and Soviet Union will make possible two new monitoring stations inside the Soviet Union to help fill in what has long been a 'seismic hole' in a worldwide earthquake-detection network.

The US-Eurasian Seismic Studies Program also allows the upgrading of five existing Soviet seismic listening stations. Altogether, the new efforts are expected to improve earthquake prediction and provide a much more detailed picture of how seismic waves propagate through the Earth in the region (see map). The data will also provide useful background in attempts to monitor underground nuclear tests.

The new agreement marks a joint effort between the US Geological Survey, the crude circle, comprise part of a 23-station global network called the International Deployment of Accelerometers that is managed by Scripps for IRIS. The new stations will fill in holes in that network by providing the first comprehensive look at two active earthquake zones. One will be installed near Frunze in the south central Soviet Union, where tectonic plates meet to form the boundary of the Indian and Asian subcontinents. The other will be in Garni, just west of the Caspian Sea near the site of the devastating earthquakes that rocked Soviet Armenia last December.

Neither station will be within 1,000 kilometres of a Soviet nuclear test ground, and will therefore have no direct bearing on the monitoring of nuclear tests, according to Scripps geophysicist Bernard Minster. But

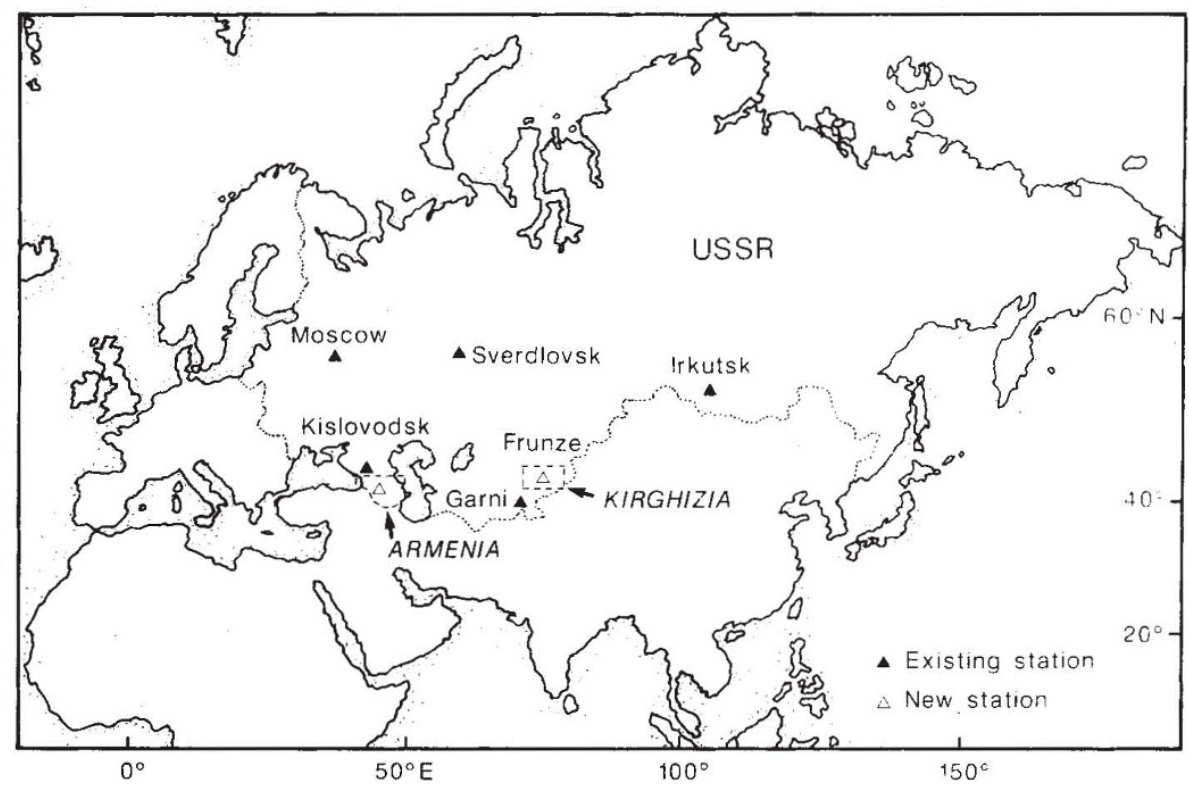

Soviet Academy of Sciences and the Incorporated Research Institutions for Seismology (IRIS), a consortium of more than 60 US universities. The five-year programme, supported by the Defense Advanced Research Project Agency (DARPA), includes a first-year budget of $\$ 5.7$ million. Most of that money will go to the Scripps Institution of Oceanography, part of the University of California at San Diego, which will coordinate and manage all IRIS operations in the Soviet Union.

The five existing sites, scattered in a he stresses that the improved model of the Earth, and of how seismic waves travel through it, will indirectly bear on any verification process. "By learning more about the Earth we all get information that will be usable by people who worry about nuclear monitoring", Minster says.

As part of the agreement, Soviet researchers will receive data from five already existing seismic stations in the United States and two new sites to be established in New Mexico and Virginia.

Robert Buderi 